\title{
Pigments based on blast furnace slag from waste water
}

\author{
Liliya Frolova ${ }^{1, *}$, Tetyana Butyrina ${ }^{1}$, and Yurii Galivets ${ }^{1}$ \\ ${ }^{1}$ Ukrainian State University of Chemical Technology, 49005, Dnipro, Haharina Ave., 8, Ukraine
}

\begin{abstract}
In this work we prove the possibility of blast furnace slag use as a basis for green, black, brown and orange pigments. We presented kinetic characteristics of the process, as well as the main characteristics of the products obtained. We found that a high degree of conversion is provided by both chemical reaction and adsorption. Through microscopic analysis we identified pigment dispersion. We worked out technological scheme of the process.
\end{abstract}

\section{Introduction}

Currently, the construction industry needs decorative building materials, which are used in the manufacture of ceramic pigments, paints, decorative glazes.

Creation of new effective and inexpensive inorganic pigments is an important task of modern materials science. Promising directions for obtaining such materials - are "coreshell" technology, structured synthesis of compounds of the transition elements, which chromophore cations are spread in the crystal lattice, production of quality products from production wastes.

Researchers are highly interested in the latest trend - obtaining pigments from available cheap raw materials. This particular waste composition necessitates a set of physicochemical and functional properties of the final product.

However, they are still scarcely studied as a potential raw material compound. Most of the research works is devoted to studying the structure and properties of pigments produced from high-grade expensive raw materials [1-5].

The scientific and practical interest is to obtain and study the compounds of the transition elements, such as iron oxide, zinc and chromium. Injection of variable valence cations and use of a so-called "core" of the fine slag as a base could provide new inorganic pigments.

Annually, metallurgical, engineering and chemical industries stockpile thousands of tons of solid waste, which in many cases can be considered as technogenic raw-material for other technologies, including for the production of pigments and decorative building materials [6]. An urgent issue is the integrated use of raw materials and development of non-waste production.

There are a number of works devoted to this issue. For example, ceramic pigments, which are waste generated microgranules were synthesized during the optical polishing of

*Corresponding author: 19kozak83@gmail.com 
glass, the surface is covered with two layers - silica and crystals $\alpha-\mathrm{Fe}_{2} \mathrm{O}_{3}, \alpha-\mathrm{Al}_{2} \mathrm{O}_{3}$ and $\mathrm{FeAl}_{2} \mathrm{O}_{4}$ [7]. Such pigments can be used for enamels manufacturing. Also sphene, apatite and nepheline concentrates-based pigments were obtained. [8] In [9] ceramic pigments synthesis used vanadium-containing catalyzates were used.

Chromium-containing compounds have been carefully studied in detail as ceramic pigments properties [10-12] for coloring glazes and ceramic products because of their high heat resistance and chemical resistance in combination with the optical properties.

Chromium-containing black ceramic pigments with spinel structure were obtained. Black pigments based on spinel composition $(\mathrm{Fe}, \mathrm{Co})(\mathrm{Fe}, \mathrm{Cr})_{2} \mathrm{O}_{4}$ or $(\mathrm{Ni}, \mathrm{Fe})(\mathrm{Fe}, \mathrm{Cr})_{2} \mathrm{O}_{4}$ have high heat resistance and stability properties. The authors of the work [11] examined the use of blast furnace slag as a basis for producing pigments of olive color from concentrated chromium-containing waste water.

Technology for brown color pigments production from concentrated waste water is described in detail in works [13-15]. A good alternative to commercial pigments synthesized from pure oxides are on iron oxides- based pigments obtained from pickling solutions [16]. Constantly increasing importance pigments based on iron oxides owes to their non-toxicity, chemical stability, a wide range of colors ranging from yellow, orange, red, brown to black, as well as its low cost. The work also investigates the possibility of pigments synthesis from aluminum sludge [17].

Blast furnace slag use is prospective due to its high specific surface and high basicity [18]. The abovementioned properties predetermine high adsorption and chemisorption properties of slag [19]. Development of scientific basis of the technology of obtaining pigments based on blast furnace slag will not only create new recycling technologies, but also will regulate the efficiency of processing and expand the practical use of waste. The use of blast furnace slag as adsorbents confronts researchers with studying the composition, dispersion, basicity of slag, and their influence on the properties of the pigments.

In addition, heavy metal cations, which are part of the pigments, are commonly used chromophores. It is known that the color of pigment depends not only on the chemical nature of chromophore ion injected, but also on coordination, in which it is located, and the level of symmetry of the polyhedron coordination.

The most long-lasting and bright color have spinel pigments with a cubic structure; garnets group pigments have high chromophore quality, which also crystallize in the cubic system; known are tetragonal pigments [20,21].

The aim of the present work was to investigate the possibility of obtaining deposits of pigments with spinel structure using blast furnace slag.

\section{Materials and methods}

We used the model solutions were based on nickel sulfate, iron sulfate and chromium sulfate, zinc sulfate of various concentrations $(0.7 \mathrm{~mol} / 1,0.5 \mathrm{~mol} / 1$ that $0.25 \mathrm{~mol} / \mathrm{l})$. Experiments were held in a thermostated cell at $30{ }^{\circ} \mathrm{C}$ temperature. The temperature was maintained constant by a thermostat UT-5. The concentration of metal cations in the solution was determined in complexometric way. The phase composition of the dried powder was determined by X-ray diffraction (DRON-2.0, Cu-Ka-rays), the color characteristics of the pigments were studied by the colorimetric method.

Preshedded blast furnace slag was used as a basis for the pigment.

Microscopic analysis was carried out on Remme-102 device (SELMI, Ukraine), dispersion of pigments was evaluated using the MBS-9 microscope. 


\section{Results and discussion}

In this work we studied the effect of the cation nature, initial concentration and the duration of the process on the residual concentration of heavy metals in the solution. Conditions of conduction and justification of the main modes of the experiments are given in the work [11].

In the works $[15,21-25]$ the analysis of wastes, that represents potential interest as a raw material for the production of pigments is made. The use of granulated blast furnace slag as a "core" is determined by high stability of the chemical composition.

Blast furnace slag is a waste of a huge amount, and includes such essential minerals: ghelenite, gardistonite, okermanite relating to melilite group. These are orthosilicates having in the basis of the structure silicon-oxygen motives of the isolated doubled tetrahedra. The composition of melilite can be regarded as an intermediate mineral species in the isomorphic series, the finite members of which are gehlenite okermanite: $\mathrm{Ca}_{2}\left[\mathrm{Al}_{2} \mathrm{SiO}_{7}\right] \ldots \mathrm{Ca}_{2}\left[\mathrm{Mg}_{2} \mathrm{SiO}_{7}\right] . \mathrm{Mg}^{2+}$ ion in the structure of okermanite is iso-morphically replaced by ion $\mathrm{Al}^{3+}\left(\mathrm{Zn}^{2+}\right)$, while the replacement of one ion $\mathrm{Si}^{4+}$ by ion $\mathrm{Al}^{3+}$, thus achieving electrostatic neutrality of the structure. Cations $\mathrm{Mg}^{2+}$ or $\mathrm{Al}^{3+}$ are located at the nodes and in the center of the square where each is surrounded by four oxygen ions. $\mathrm{Ca}^{2+}$ ions are surrounded by eight oxygen ions.

Chemical analysis of the slag sample of one of the metallurgical enterprises of Ukraine showed (Table. 1) that its main components are $\mathrm{CaO}$ and of $\mathrm{SiO}_{2}$, the total content of which is 84.5 wt. $\%$.

Table 1. Chemical composition of samples of blast furnace slag.

\begin{tabular}{|c|c|}
\hline Component & Weight, $\%$ \\
\hline $\mathrm{SiO}_{2}$ & 38.6 \\
\hline $\mathrm{Al}_{2} \mathrm{O}_{3}$ & 7.16 \\
\hline $\mathrm{CaO}$ & 46.04 \\
\hline $\mathrm{MgO}$ & 4.91 \\
\hline $\mathrm{FeO}$ & 0.49 \\
\hline $\mathrm{Fe}_{2} \mathrm{O}_{3}$ & 0.28 \\
\hline $\mathrm{TiO}_{2}$ & 0.22 \\
\hline $\mathrm{K}_{2} \mathrm{O}$ & 0.51 \\
\hline $\mathrm{Na}_{2} \mathrm{O}$ & 0.32 \\
\hline $\mathrm{SO}_{3}$ & 1.61 \\
\hline
\end{tabular}

The phase composition of the investigated slag, according to analysis conducted by Xray diffraction, was represented mainly by the amorphous glass phase (97-98\%), which has a small amount of crystalline formations in the form of a solid solution of melilite and calcium silicate and xonotlite structure $\left(6 \mathrm{CaO} 6 \mathrm{SiO}_{2} \mathrm{H}_{2} \mathrm{O}\right)$ with characteristic diffraction lines. The said calcium hydrosilicate is a product of slag minerals hydration and is formed during wet granulation of the slag melt, and further extended stay in the dumps.

High basicity of slag provides the $\mathrm{pH}$ of the solution necessary for the formation of 
sparingly soluble hydroxides $\mathrm{Me}(\mathrm{OH})_{\mathrm{n}}$, in addition the presence of polysilicic acids, increases process efficiency. Having well-developed surface area, polysilicon acid form colloidal particles capable of reacting with metal ions to form hydroxosilicates.

These reactions are of a general nature and are not always suitable for the interpretation of kinetic studies presented in Figures 1, 2, 3, as chromophores cations are of different nature and, accordingly, different chemisorbing ability on the surface of the slag particles.

In the first phase of research was determined the ability of slag to bind iron, chromium, nickel and zinc cations.

Based on these data, we can say that the course of the curves is determined by a heavy metal cation nature and is of similar nature. For dependence of conversion degree from time, for chromium cations high speed of the process is observed on the first area corresponding to chemical reaction, and the second phase - coagulation and adsorption of the product on the surface of the slag.

Iron cations in all concentrations do not reach high degree of purification. This can be attributed primarily to the formation of colloidal ferric hydroxide solution (III) which is poorly coagulated and adsorbed on the surface of slag. In this case, in order to achieve high purity it takes a long settling for suspension.

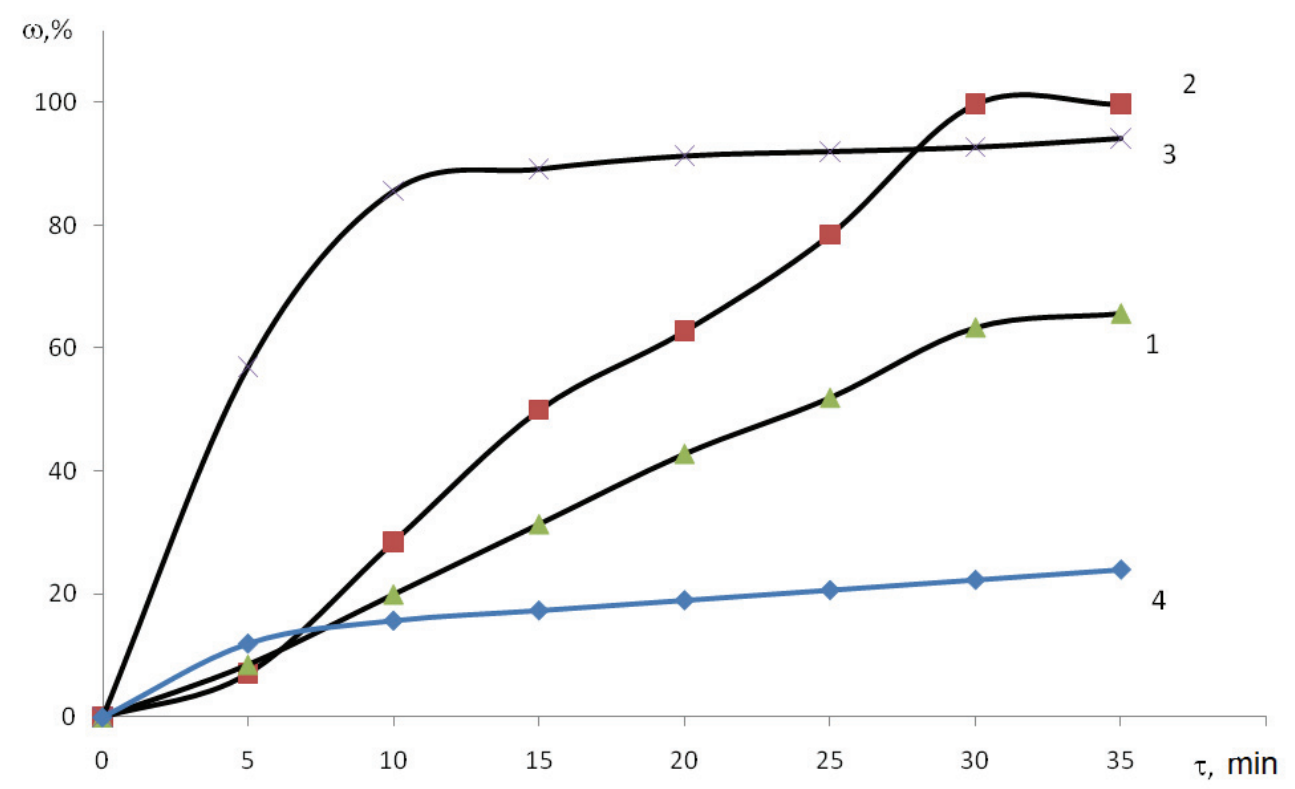

Fig. 1. The dependence of the concentration of heavy metal cations from time: 1 - solution of ferrous sulfate, 2 - nickel sulfate solution, 3 - a solution of chromium sulphate, 4 - zinc sulphate solution.

Formation of nickel compounds is passing at high degree for all concentrations, but it requires a long settling. As heavy metals hydroxides form stable colloidal systems, to intensify the process of their deposition in the wastewater coagulants as usually added. The possible reactions can take place with different cations:

$$
\begin{aligned}
\mathrm{CaO}+\mathrm{H}_{2} \mathrm{O} & \rightarrow \mathrm{Ca}(\mathrm{OH})_{2}, \\
\mathrm{MgO}+\mathrm{H}_{2} \mathrm{O} & \rightarrow \mathrm{Mg}(\mathrm{OH})_{2}, \\
\mathrm{NiSO}_{4}+\mathrm{Ca}(\mathrm{OH})_{2} & \rightarrow \mathrm{CaSO}_{4}+\mathrm{Ni}(\mathrm{OH})_{2} \\
\mathrm{NiSO}_{4}+\mathrm{Mg}(\mathrm{OH})_{2} & \rightarrow \mathrm{MgSO}_{4}+\mathrm{Ni}(\mathrm{OH})_{2}
\end{aligned}
$$




$$
\begin{aligned}
& 2 \mathrm{Ca}_{2} \mathrm{SiO}_{4}+4 \mathrm{NiSO}_{4}+4 \mathrm{H}_{2} \mathrm{O} \rightarrow 2 \mathrm{Ni}_{2} \mathrm{SiO}_{4}+4 \mathrm{CaSO}_{4} \mathrm{H}_{2} \mathrm{O} \\
& 2 \mathrm{Ca}_{3} \mathrm{SiO}_{5}+6 \mathrm{NiSO}_{4}+6 \mathrm{H}_{2} \mathrm{O} \rightarrow 2 \mathrm{Ni}_{3} \mathrm{SiO}_{5} \cdot 6 \mathrm{CaSO}_{4} \mathrm{H}_{2} \mathrm{O}
\end{aligned}
$$

The colloidal particles of hydroxides have a negative charge, so the use of coagulation electrolytes with multiply charged cations (usually it is aluminum or ferric sulfates) can significantly speed up the process. We can assume that in this case slag performs the role of coagulant accelerating the cleaning process. Above all, for colloidal compounds of chromium and nickel. It was not possible to get pigments based on zinc compounds in this case. Precipitation of zinc compounds does not occur even in an alkaline medium - up to $p H=10$.

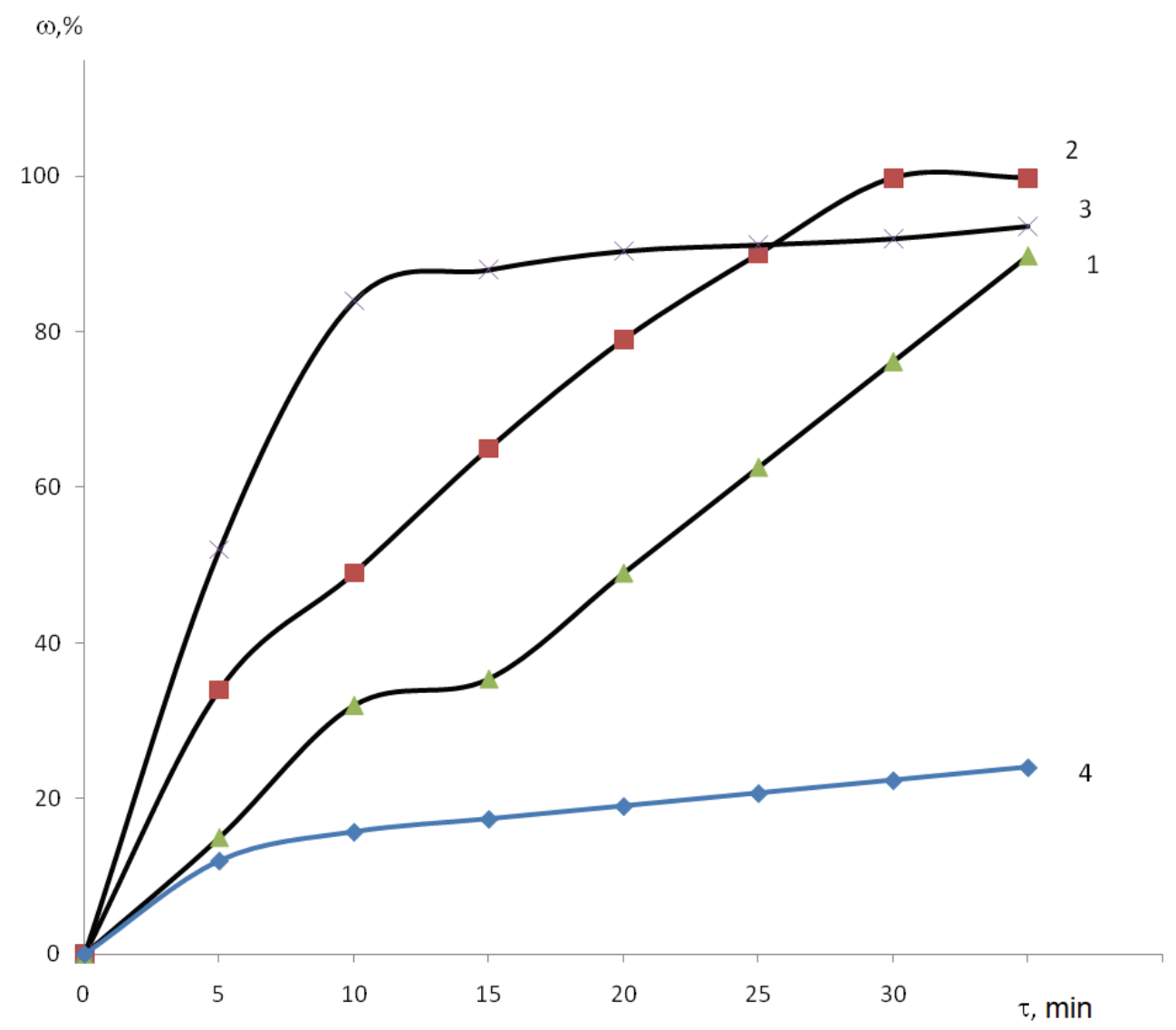

Fig. 2. The dependence of the concentration of heavy metal cations from time: 1 solution of ferrous sulfate, 2 - nickel sulfate solution, 3 - a solution of chromium sulphate, 4 - zinc sulphate solution.

Moreover, excessive alkaline environment is also unfavorable for the deposition of zinc hydroxide compounds as their solubility begins to grow in an alkaline environment even at $p H>8.5-9.0$ - due expressed amphoteric properties of that element. Thus, it can be assumed that only the alkali metal silicates can destroy complex zinc compounds and transfer them into precipitate. In this case, there is another solution-precipitant reagent for divalent ions silicate ion. Although there is no precise data on the solubility of zinc silicates, they are evaluated in reference books as "insoluble". However, the low degree of conversion is associated their low concentration in the solution. 


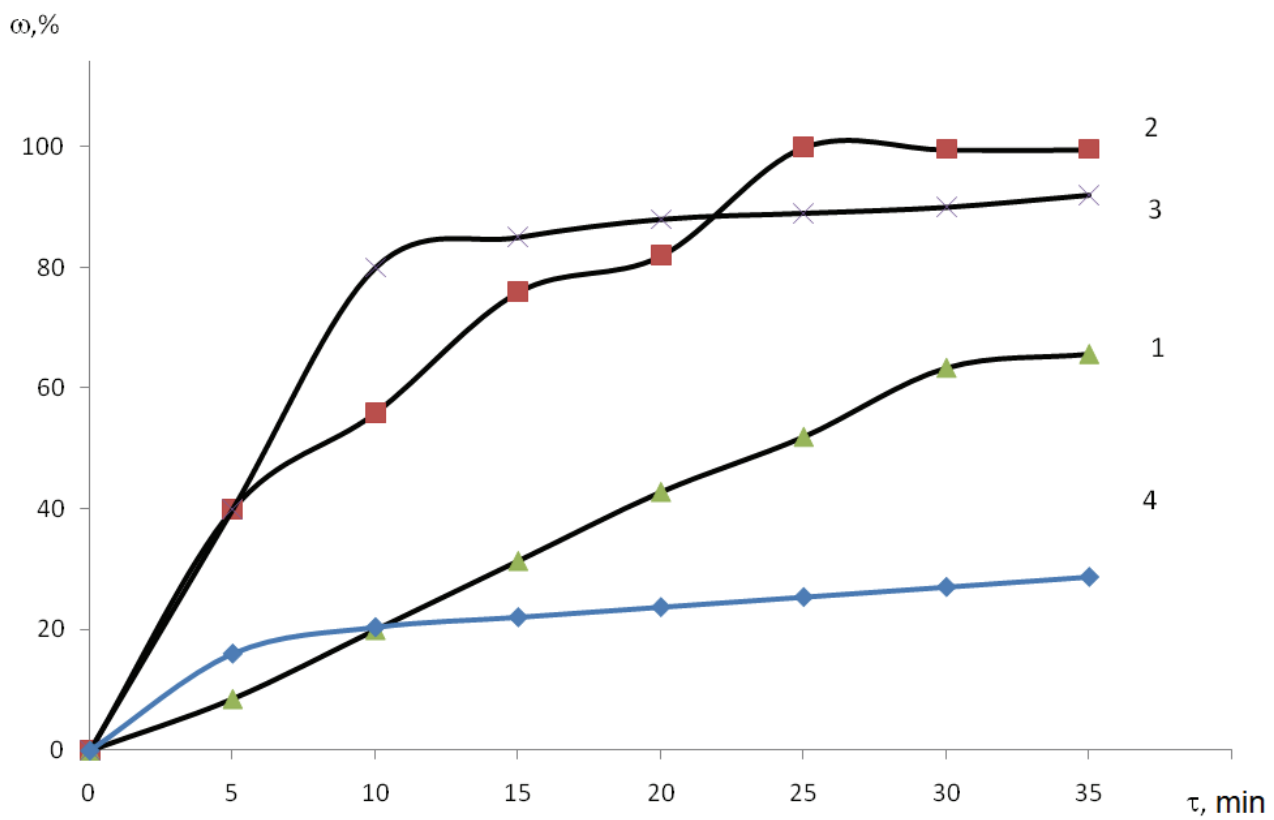

Fig. 3. The dependence of the concentration of heavy metal cations from time: 1 - solution of ferrous sulfate, 2 - nickel sulfate solution, 3 - a solution of chromium sulphate, 4 - zinc sulphate solution.

$$
\mathrm{Zn}^{2+}+\mathrm{SiO}_{3}{ }^{2-}=\mathrm{ZnSiO}_{3} \downarrow
$$

Microscopic analysis was performed to determine the particulate composition of the compounds formed, which showed that disperse pigment composition is determined by the size of the original slag grinding. As seen in Figure 4a, the base of the resulting pigment is slag, on the surface of which the corresponding hydroxide particles are chemisorbed. During the subsequent thermal processing such structure as "core-shell" is formed. To determine the chemical composition of the formed compounds we performed microscopic analysis which showed that the system is two-phase (Fig. 4b - 5).

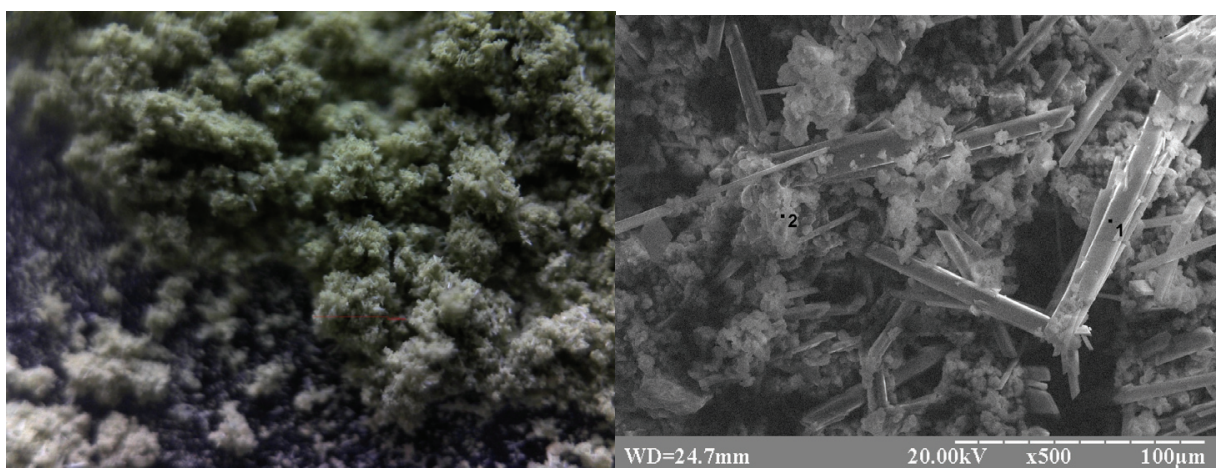

Fig. 4. The microphotograph of the particles of the obtained pigment on the basis of blast-furnace slag (nickel sulfate solution) a - surface of slag, $\mathrm{b}$ - particles of the obtained pigment on the basis of blastfurnace slag.

Phase \#1 is depleted by nickel and contains silicates and sulfates of calcium, phase \#2 is enriched in nickel and is apparently presented by hydroxides and silicates.

Under the interaction with concomitant sulfate ions, calcium hydroxide forms a 
thermally stable and neutral (relative to the pigment) compound.6 chemisorption on the slag surface is confirmed.

Under the investigation of the formed precipitate it was ascertained that the granulometric composition of the obtained pigment is defined by the size of blast furnace slag particles and is $2-4$ microns.

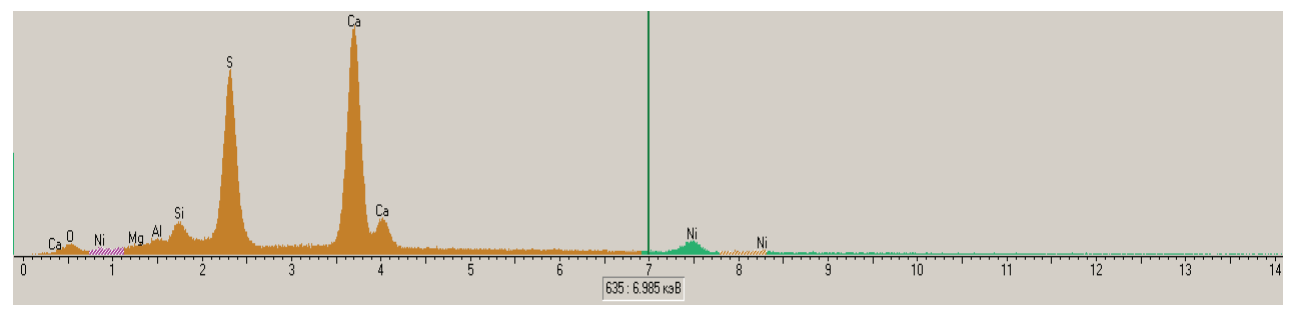

a)

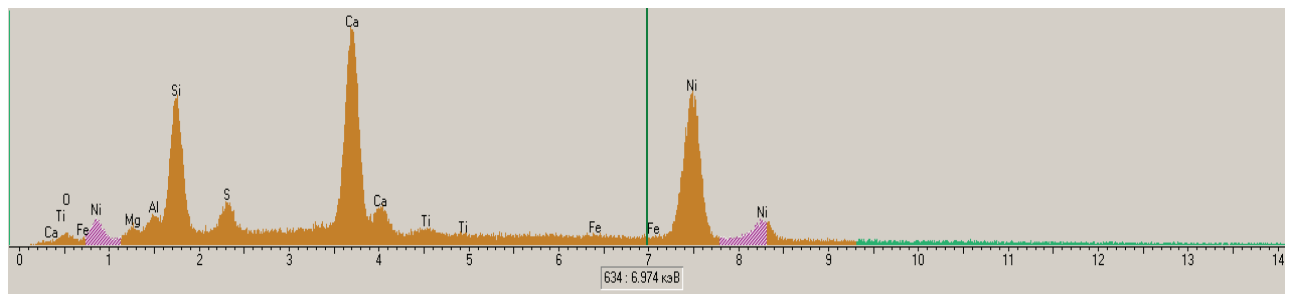

b)

Fig. 5. Elementwise composition of the powders (a - phase 1 and b - phase 2, Figure 4).

This confirms the combination of chemical interaction on the first stage with further chemisorption of precipitant on the surface of slag deposit on surfaces with total degree of nickel cations extraction 98-99 \% nickel, chromium cations - 89-96\% iron cations - 60$84 \%$, zinc - $20-21 \%$.

The main technological properties of the pigment are its color characteristics. Cations of chromium, iron and nickel are conventionally used in a technology for obtaining a chromophore pigments. Therefore, further we investigated the effect of synthesis conditions on the color scale and intensity. The phase composition of the starting slag, calcined and uncalcined pigment has fundamental differences: the initial slag - amorphous solution treated has a peak corresponding to aluminum and silicon compounds, the final product has peaks corresponding to the color-forming complex compounds formed during sintering.

The intensity of staining pigment depends largely on the nature of the chromophore cation, the ratio of $n=$ Slag: $\mathrm{Me}^{\mathrm{n}+}$ and less on the duration of the process.

Table 2. The dependence of the color characteristics on the experimental conditions.

\begin{tabular}{|c|c|c|c|c|c|c|c|c|c|}
\hline \multirow{2}{*}{$\begin{array}{c}\text { Cation- } \\
\text { chromophore }\end{array}$} & Color & \multicolumn{8}{|c|}{ Optical characteristics } \\
\cline { 3 - 10 } & & $\begin{array}{c}S R, \\
\%\end{array}$ & $X$ & $Y$ & $Z$ & $x$ & $y$ & $P, \%$ & $\begin{array}{c}\lambda, \\
\mathrm{nm}\end{array}$ \\
\hline Chrome & Olive-green & 46.11 & 51.88 & 46.31 & 10.90 & 0.4755 & 0.4244 & 32 & 584 \\
\hline Nickel & Dark-brown & 83.6 & 17.63 & 14.03 & 4.463 & 0.4880 & 0.3883 & 5 & 618 \\
\hline Zink & Opaline & 94.25 & 102.7 & 93.86 & 32.73 & 0.4479 & 0.4093 & 1 & 700 \\
\hline
\end{tabular}

The research made it possible to develop a schematic flow diagram of the process of obtaining pigments based on blast furnace slag (Fig. 6). Sewage waters enter reactor 2 when the mixer is on previously ground slag is added. 


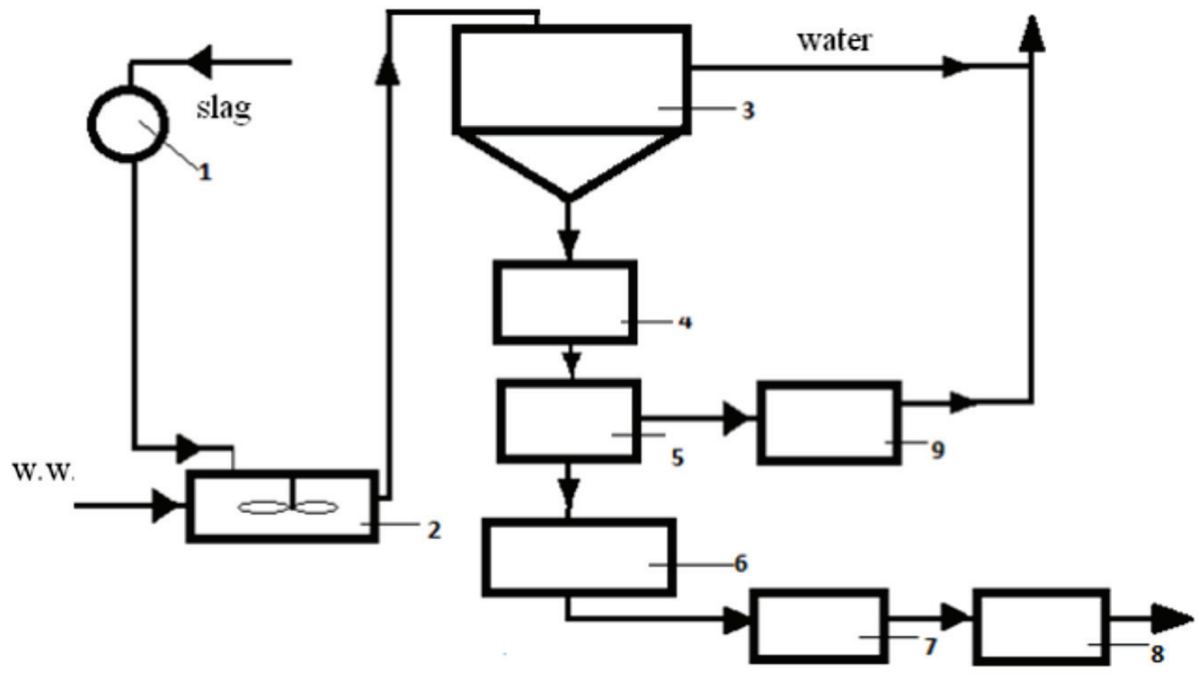

Fig. 6. Process flow diagram of wastewater treatment: 1 - slag feeder; 2 - reactor; 3 - vertical sump; 4 - slurry tank; 5 - filter press; 6 - dryer 7 - furnace; 8 -mill; 9 - a mechanical filter; WW - waste water; PW - purified water.

After completion of the process of heavy metal cations chemisorption slurry is fed into a vertical slump 3, some of the treated water gets into the process. The completion of the process is indicated by the absence of heavy metal ions in the mother solution.

The precipitate is sent to the slurry tank 4 , and then to a filter-press 5 . The output from the filter press then goes to the dryer 6 , and the mother solution to a mechanical filter 9 . Water from the filter goes in the mechanical process.

The pigment obtained goes from the dryer to the furnace 7, and further to the mill-8, the final product goes into production.

\section{Conclusion}

Thus, as a result of the study the possibility of obtaining green and brown pigment based on blast furnace slag with a conversion degree of 97-98 \% was stated. An important process parameter is the disperse and phase basic slag composition, as rheological properties of the pigment depend on them. These patterns make it possible to get the pigments from light olive to deep green by varying the synthesis parameters.

\section{References}

1. G.L. Pashkov, S.V.Saikova, M.V. Panteleeva, E.V. Linok, A.S. Samoilo, G.N. Bondarenko, Glass Ceram., 70, 225-228 (2013)

2. I.S. Ahmed, S.A. Shama, M.M. Moustafa, H.A. Dessouki, A.A. Ali, Spectrochim. Acta Part A, 74, 665-672 (2009)

3. F. Matteucci, G. Cruciani, M. Dondi, M. Raimondo, Ceram. Int., 32, 385-392 (2006)

4. M. Dondi, G. Cruciani, G. Guarini, F. Matteucci, M. Raimondo, Ceram. Int., 32, 393405 (2006)

5. M. Kurzawa, E. Tomaszewicz, Spectrochim. Acta Part A, 55, 2889-2892 (1999)

6. J.M. Magalhaes, J.E. Silva, P.C. Fernando, J.A. Labrincha, J. of Environ. Manag., 75, $157-166(2005)$ 
7. E.V. Shynkareva, V.D. Koshevar, O.L. Zhygalova, Yu.G. Zonov, Steklo y keramyka, 12, 26-28 (2006)

8. L.G. Gerasymova, Y.V. Lazareva, A.Y. Alekseev, L.A. Galtnurova, Stroytel’nye materyaly, 4, 32-34 (2002)

9. M.B. Sedelnikova, N.V. Liseenko, Y.I. Pautova, V.M. Pogrebenkov, J. Waste Manage., 4, 6-8 (2013)

10. N. Muñoz, N. Masó, B. Julián, F. Márquez, H. Beltrán, P. Escribano, E. Cordoncillo, J. Eur. Ceram. Soc., 24, 2087-2094 (2004)

11. L.A. Frolova, A.A. Pivovarov, T.E. Butirina, J. Water Chem. Technol., 37, 342-351 (2015)

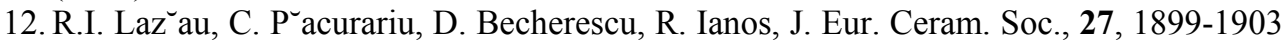
(2007)

13. L.A. Frolova, A.A. Pivovarov, E.A. Tsepich J. Chem. Technol. Metall., 51, 163-167 (2016)

14. L.A. Frolova, A.A. Pivovarov, A.S. Baskevich, Russ. J. Appl. Chem., 87, 1054-1059 (2014)

15. L.A. Frolova, A.A. Pivovarov, Chem. Chem. Technol., 10, 209-212 (2016)

16. L.A. Frolova, Metall. and Min. Ind., 4, 65-69 (2014)

17. A.P. Novaes, Brazil Am. Ceram. Soc. Bull., 5, 9501-9503 (2005)

18. S.V. Nesterenko, N.A. Ovchy`nny`kov, V.M. Xomenko, Fyzycheskye svojstva metallurgycheskyh shlakov. Spravochnoe yzdanye, Doneczk, (2001)

19. A.P. Zosyn, B.Y. Gurevych, Y.B. Mylovanova, Xymyya y texnologyya sylykatnyh materyalov, 7, 100-105 (1971)

20. G.N. Maslennikova, Glass Ceram., 58, 216-220 (2001)

21. Y. Marinova, J.M. Hohemberger, E. Cordoncillo, P. Escribano, J.B. Carda, J. Eur. Ceram. Soc., 23, 213-220 (2003)

22. F. Andreola, L. Barbieri, F. Bondioli, Dyes Pigments, 94, 207-211 (2012)

23. E. Ozel, S. Turan, S. Coruh, N.O. Ergun, Waste Manage. Res., 24, 125-133 (2006).

24. L.A. Frolova, N.N. Shapa, Metall. Min. Ind., 3, 287 (2011)

25. L.A. Frolova, V.A. Shuvalov, Chem. Chem Technol., 7, 235-239 (2013) 